\title{
Determinants of Cardiovascular Disease among Urban Women with Psoriasis: A Case-Control Study
}

\author{
Sudha Bala ${ }^{1}$ Archana Mavoori ${ }^{2}$ Harshal Pandve ${ }^{1} \quad$ Chinmayee Biswal $^{3}$ Vijay Prasanna ${ }^{4} \quad$ Suneeth Jogi ${ }^{3}$ \\ ${ }^{1}$ Department of Community Medicine, ESIC Medical College, \\ Sanathnagar, Hyderabad, Telangana, India \\ 2Department of Dermatology, ESIC Medical College, Sanathanagar, \\ Hyderabad, Telangana, India \\ ${ }^{3}$ Department of Radio-diagnosis, ESIC Medical College, \\ Sanathanagar, Hyderabad, Telangana, India \\ ${ }^{4}$ Department of Rheumatology, ESIC Medical College, \\ Sanathanagar, Hyderabad, Telangana, India \\ Address for correspondence Sudha Bala, MBBS, MD, Flat No301, \\ 2-2-1075/A, Shubodaya enclave, Baghamberpet, Hyderabad, \\ 500013, Telangana, India (e-mail: dr.sudhabala78@gmail.com). \\ Ind J Car Dis Wom:2020;5:102-108
}

\begin{abstract}
Keywords

- cardiovascular disease

- psoriasis

- HsCRP

- CIMT

- psoriatic arthritis
\end{abstract}

Background and Aim Psoriasis have a direct impact on development of cardiovascular risk factors leading to atherosclerosis and metabolic abnormalities. In order to prevent the complications, early and prompt identification of factors through various parameters help in primary and secondary prevention of cardiovascular diseases (CVDs) among these psoriatic patients. Therefore the aim of this study is to determine the prevalence of various determinants for cardiovascular diseases among cases and controls.

Methods A hospital based case control study at a tertiary care hospital included women from the out patient department, aged above 18 years who were known cases of psoriasis. 114 patients were recruited with 1:1 ratio between cases and controls. All patients were evaluated using semi structured interview schedule with socio demographic variables, duration of disease, family history, and usage of drugs. Severity of disease was assessed through the psoriasis area severity index (PASI). Body surface area (BSA), body mass index (BMI), waist circumference and blood pressure measurement were done using standard methods. Lipid profile, high sensitivity C-Reactive protein (HsCRP) and blood sugar through calibrated analyzers having quality control. Carotid intima media thickness (CIMT) was assessed by using carotid Doppler technique to measure atherosclerosis.

Results One hundred fourteen patients, means 57 pairs of cases and controls were analyzed in this study. Significant determinants among cases were raised such as waist circumference $(p=0.025)$, diastolic blood pressure $(p=0.0001)$, low density lipoprotein $(p=0.002)$ and fasting blood glucose $(p=0.004)$ when compared to controls. HsCRP and CIMT were also raised among cases but only CIMT was statistically significant when compared to controls $(p=0.0001)$. We also found raised determinants among psoriatic arthritis patients compared to psoriasis.

Conclusion Psoriasis patients had high waist circumference, diastolic blood pressure, low density lipoprotein, fasting blood glucose, and CIMT when compared to controls. Early identification of these determinants make them amenable for prevention. 


\section{Abstract Image}

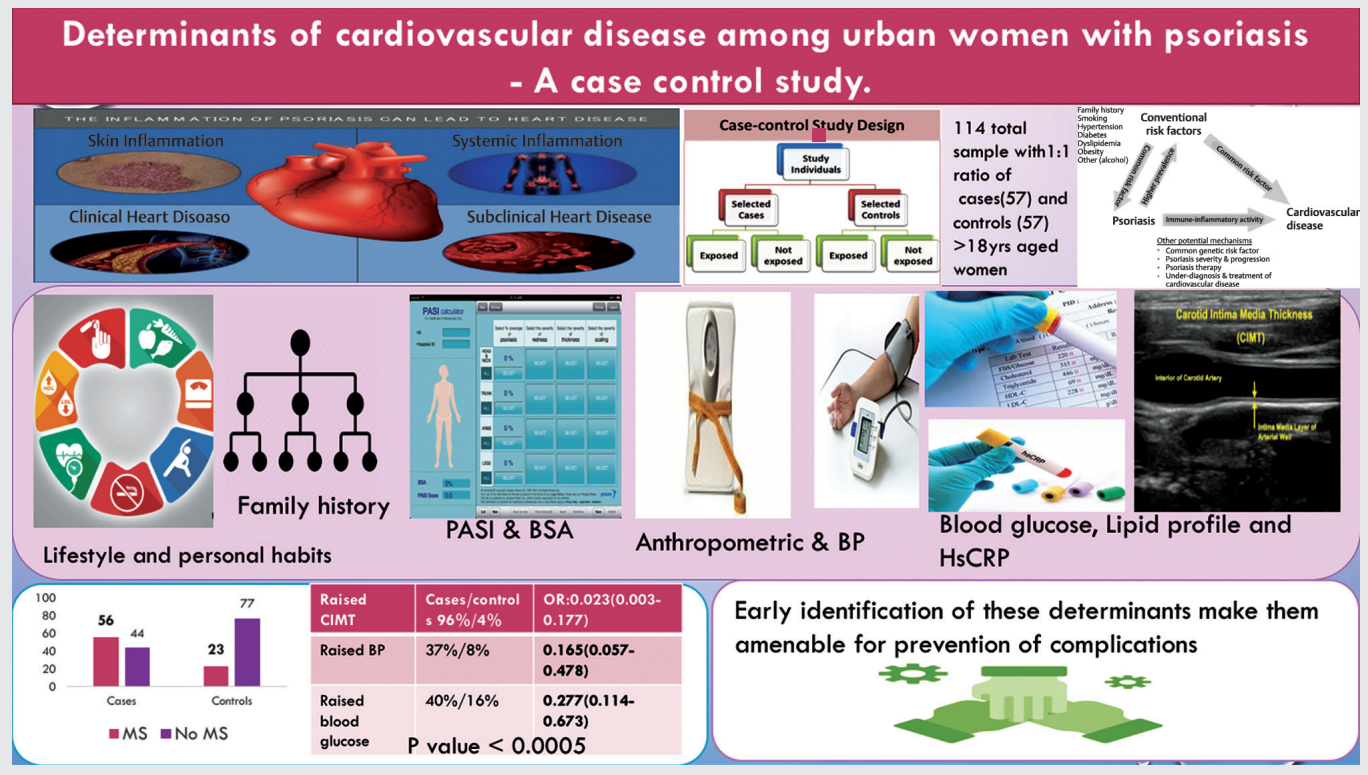

\section{Introduction}

Psoriasis is a chronic inflammatory immune-mediated skin disease with complex etiology. Genetic predisposition and familial clustering have been proven to be associated with psoriasis. ${ }^{1}$ Environmental factors responsible for psoriasis are psychological stress, obesity, tobacco and alcohol usage, streptococcal and viral infections, lack of sunlight, trauma, and usage of certain medications such as lithium, beta-blockers, and antimalarial drugs. ${ }^{2}$

According to global psoriasis atlas 2019, the prevalence of psoriasis among adults varies from $0.17 \%$ in East Asia to 2.5\% in Western Europe. Among South Asians 1.73 billion are affected and in India 1.34 billion are affected with the prevalence of $0.37 \%(0.007-1.85 \%){ }^{3}$ All member states of World Health Organization (WHO) have recognized the burden of psoriasis as a major public health problem affecting the quality of life. The main barriers were incorrect or delayed diagnosis, inadequate treatment options, and insufficient access to health care. This encouraged to raise the awareness regarding the disease process and fighting off stigmatization suffered by these people through the global report of $2016 .{ }^{4}$

Commonly used measures for scoring the severity of psoriasis include the psoriasis area and severity index (PASI) and the physician global assessment. Clinicians assess the severity of the disease, taking into account the degree of scaling, redness, thickness of the skin lesions, or the size of the body surface area (BSA) occupied by psoriasis. ${ }^{5}$

Psoriasis is associated with increased cardiovascular disease (CVD) risk because of common pathogenic mechanisms such as Th1 and Th17 cytokine upregulation, T-cell activation, local and systemic expression of adhesion molecules, and endothelin contributing to the development of lesions. ${ }^{6}$ Carotid intima media thickness serves as an intermediate risk factor which is used as a surrogate marker to predict subclinical atherosclerosis. ${ }^{7}$ The high sensitivity C-reactive protein (HsCRP) is the most widely evaluated biomarker for global CVD risk prediction.

Moreover, women are more prone to develop this metabolic syndrome which is a major determinant of CVD compared with men mainly due to preponderance to develop central obesity. Identification of these risk factors is very essential to prevent complications and poor management of CVDs especially among women.

There is paucity of data on assessment of various determinants of CVDs specifically among women suffering with psoriasis in Hyderabad. Therefore, an attempt has been made with an objective to assess various determinants of CVDs among psoriasis patients and controls.

\section{Material and Methods}

A hospital-based case-control study conducted at tertiary care hospital of Hyderabad for a period of 3 months included women aged above 18 years who were known diagnosed cases of psoriasis attending outpatient block of specialty clinic in the department of rheumatology and dermatology with willingness to participate and free from any of the CVDs were taken as cases, and women above the age of 18 years who were attending general medicine outpatient department free from any of the rheumatologic and skin diseases were considered as controls. 
Taking the major cardiovascular determinant-metabolic syndrome as the proportion of exposed controls to calculate the sample size using Open Epi, we had taken $15 \%$ of proportion among females from one of our Indian study ${ }^{8}$; thereby the sample size was 114 with 57 pairs maintaining 1:1 ratio between cases and controls.

Simple random sampling method was used for recruiting the participants. A total of 145 participants (60 cases and 85 controls) were contacted and explained about the importance of the study among women at outpatient block of our hospital. Of this, desired sample of 57 pairs was included in our study.

Institutional ethical committee approval and written consent from the participants were taken after explaining the purpose of the study. Data were collected by the trained faculty under the guidance of dermatologist and rheumatologist using a predesigned, pretested, and precoded questionnaire which consisted of sociodemographic variables, duration of disease, family history, usage of drugs; Severity of disease is done through PASI, BSA, body mass index(BMI), waist circumference (WC), blood pressure measurement using standard methods, lipid profile, HsCRP, blood glucose through calibrated analyzers having quality control. carotid intima media thickness (CIMT) was also measured by using carotid Doppler technique. Metabolic syndrome was defined as per the updated Adult Treatment Panel III (ATPIII) criteria which include three or more of the following: triglyceride $\geq 150 \mathrm{mg} / \mathrm{dL}$, high-density lipoprotein (HDL) cholesterol $<50 \mathrm{mg} / \mathrm{dL}$ in women, fasting glucose $\geq 100 \mathrm{mg} / \mathrm{dL}$, or previously diagnosed with type 2 diabetes, blood pressure $\geq 130 / 85 \mathrm{~mm} \mathrm{Hg}$, or antihypertensive medication and central obesity (defined as WC $\geq 80 \mathrm{~cm}$ in women, according to the ethnic criteria for Asians). ${ }^{9}$ Interview questionnaire schedule was developed after pilot testing and necessary changes were incorporated.

As per PASI, head, arms, trunk, and legs were classified with grade 0 to 6 : Grade 0 as $0 \%$ of involved area, grade $1<10 \%$, grade $2(10-29 \%)$, grade $3(30-49 \%)$, grade 4 (50-69\%), grade 5 (70-89\%), and grade 6 (90-100\%). Anthropometric measurements using standardized methods were measured. Weight was measured closer to $0.1 \mathrm{~kg}$ in light clothing using a bathroom scale (Camry scale) and their height measured with a height measuring rod without wearing foot wear to the nearest $0.1 \mathrm{~cm}$. BMI was calculated according to Asians classification. ${ }^{10}$ The WC was measured using a tape in a horizontal plane, midway between the inferior margin of the ribs and the superior border of the iliac crest for central obesity assessment. A single blood pressure measurement was done by using standardized procedures in sitting position on right arm using a digital sphygmomanometer (OMRON IAI) which was standardized everyday with diamond mercury sphygmomanometer. If found on higher side an average of three readings was taken with 10 minutes apart and blood pressure levels were classified as per Joint National Committee $7 .^{11}$

\section{Biochemical Profiles}

Fasting blood sugar and lipid profile after overnight fasting of 10 to 12 hours was measured at our hospital. Measurements were done using Cobas C 311 autoanalyzer which involves calorimetric principle for measuring lipid profile and ultraviolet test enzymatic reference method with hexokinase for measuring blood glucose. A total of $3 \mathrm{~mL}$ of blood was collected using plain and fluoride containers.

\section{Highly Sensitive C-Reactive Protein}

A total of $2 \mathrm{~mL}$ of blood was collected using plain tubes and measurement was done using Cobas Integra 400+ involving immune turbidometry method.

\section{Carotid Intima Media Thickness}

DC 60 model of Mindray company has been used to measure incorporating advanced ultrasound systems with optimal image quality and a wide range of application capabilities.

Those who were found to have abnormal biochemical and ultrasound (CIMT) findings were referred to the cardiologist at ESIC, super specialty hospital within the campus. They were also advised and educated about the disease process and to maintain adherence to treatment along with preventive strategies to promote healthy life.

\section{Statistical Analysis}

Data were entered and analyzed using Microsoft Excel 2015. Frequency, mean \pm standard deviation, odds ratio were calculated wherever required. Comparison was made among psoriasis cases and controls. Prevalence of individual components of metabolic syndrome was calculated using mantel Haenszel odds ratio estimate to have better understanding. Subpopulation was also assessed among cases as psoriasis and psoriatic arthritis patients.

\section{Results}

Our study included 114 women consisting of 54 cases of psoriasis and 54 controls in 1:1 ratio who were free from coronary artery disease and stroke.

Mean age of the cases was found to be $40.70 \pm 10.95$ years and controls was $33.42 \pm 6.96$ years, respectively. According to religion the cases were Hindus 48 (84\%), Muslims 5 (9\%), and Christians 4 (7\%) and among controls-Hindus were 42 (74\%), Muslims 4(7\%) and Christians 11 (19\%), respectively. As per their marital status the cases included-6 (10\%) unmarried, 45 (80\%) married, 6 (10\%) widows and controls included-unmarried 16 (27\%), married 40 (70\%), and 1 (3\%) widows. Among psoriatic patients illiterates were 25 (44\%) and literates 32 (56\%) and controls-illiterates 14 (25\%) and literates 43 (75\%). Working group among cases was contributed by 25 (44\%) and nonworking group 32 (56\%); Controls included working group with 55 (97\%) and 2 (3\%) as nonworking group. Based on modified BG Prasad's classification cases 16 (28\%) belonged to upper class, 18 (32\%) belonged to upper middle class, and 23 (40\%) middle class; Among controls 28 (49\%) belonged to upper class, 11 (19\%) upper middle class, 12 (22\%) middle class, and 6 (10\%) to upper lower class. Psoriasis among our study subjects manifested as plaque psoriasis/psoriasis vulgaris among 29 (51\%), followed by psoriatic arthritis 14 (25\%), palmoplantar 12 (21\%), and guttate 2 (3\%). Body surface area of minimum $1 \%$ was found 


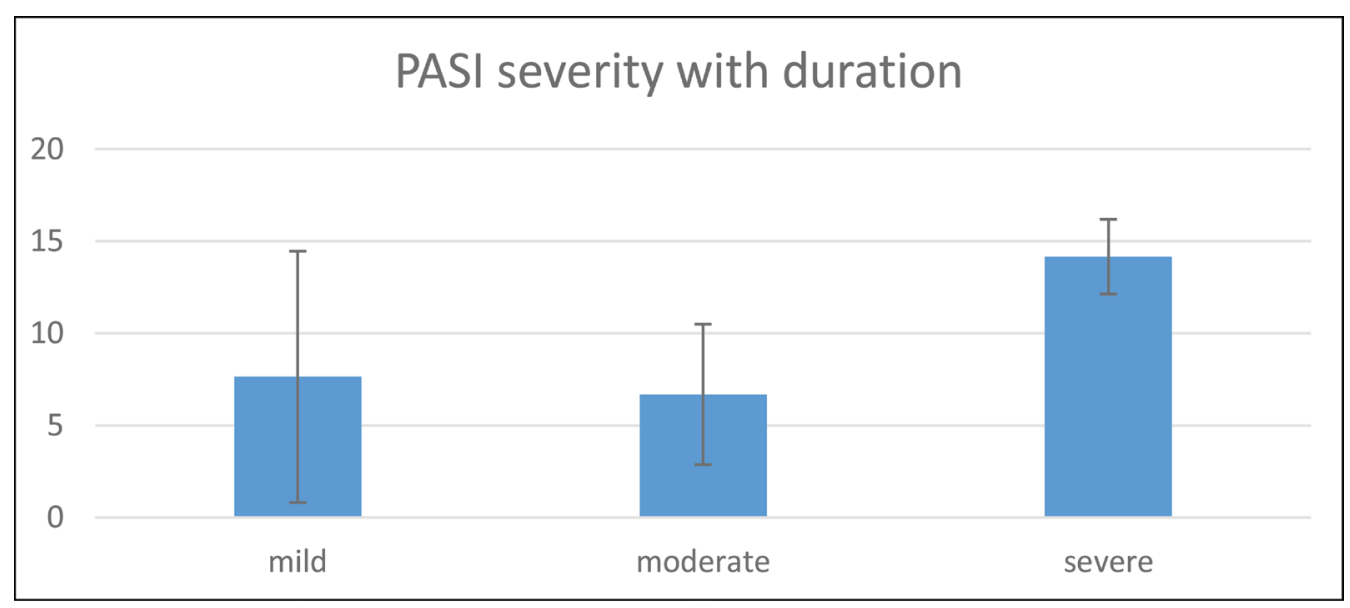

Fig. 1 Relationship between PASI score and duration. Mean scores of PASI with duration of disease statistically significant ( $p$-value: 0.004). PASI, psoriasis area severity index.

among 6 (10\%) and maximum of 5\% among 8 (14\%) mean PASI score was $7.14+3.22$ and mean duration of disease was $7.75 \pm$ 5.23 years. PASI score was found to be increasing with duration which was statistically significant (

Traditional, biochemical, and ultrasonographical determinants of CVDs among psoriasis patients and controls were assessed using independent $t$-test as detailed in - Table $\mathbf{1}$. There was a statistical significance with determinants such as WC, diastolic blood pressure, and LDL.

Alcohol usage was found among 2 (3.5\%) of cases and none among controls; tobacco usage was found among 4 (7\%) of cases and 2 (3.5\%) of controls; sedentary 22 (38\%) and moderate lifestyle 35 (62\%) were equally found among cases and controls; extraphysical activity was found only among controls 22 (38\%); history of hypertension 6 (10\%) among cases and $1(2 \%)$ controls; history of diabetes mellitus was found only among cases $8(14 \%)$. Others included family history of hypertension/diabetes among cases 36 (63\%) and 38 (66\%) among controls; any form of stress 15 (26\%) among cases and 14 (24\%) of controls was noted. These were small in number so no significance could be elicited.

Body mass index as per Asians classification 2 (3\%) of cases were underweight, normal were $4(7 \%)$ among cases and 10 (17\%) among controls, overweight 7 (12\%) among cases and controls equally and obese were 44 (78\%) among cases and 40 (71\%) among controls. As per joint national committee 7 prevalence of prehypertension was found among 4 (7\%) of cases and 9 (16\%) of controls; hypertension-I among 17 (30\%) of cases and 5 (9\%) of controls and hypertension-II only among $4(100 \%)$ of cases.

As per updated ATP III prevalence of metabolic syndrome was found to be higher among cases 32 (56\%) than among controls 13 (23\%) detailed in - Fig. 2.

The prevalence of individual components of the metabolic syndrome (MS) according to the presence of psoriasis is depicted in - Table 2 where WC, hypertriglyceridemia, low HDL, raised blood glucose, and raised blood pressure were significantly more prevalent in psoriasis cases as compared with controls. CIMT on right and left carotid arteries was measured and this was taken as increased if either side was above $0.07 \mathrm{~cm}$ or $0.7 \mathrm{~mm}$. This
Table 1 Various determinants of cardiovascular diseases among cases (psoriatic patients) and controls

\begin{tabular}{|l|l|l|l|}
\hline Determinants & $\begin{array}{l}\text { Cases } \\
(\boldsymbol{n}=57)\end{array}$ & $\begin{array}{l}\text { Controls } \\
(\boldsymbol{n}=\mathbf{5 7})\end{array}$ & $p$-Value \\
\hline Weight & $63.82 \pm 11.66$ & $63.14 \pm 11.43$ & 0.752 \\
\hline $\begin{array}{l}\text { Waist circum- } \\
\text { ference }\end{array}$ & $85.57 \pm 8.79$ & $82.17 \pm 7.08$ & 0.025 \\
\hline $\begin{array}{l}\text { Systolic blood } \\
\text { pressure }\end{array}$ & $119.45 \pm 32.62$ & $115.85 \pm 11.87$ & 0.436 \\
\hline $\begin{array}{l}\text { Diastolic blood } \\
\text { pressure }\end{array}$ & $83.96 \pm 9.96$ & $77.86 \pm 7.45$ & 0.0001 \\
\hline $\begin{array}{l}\text { Total choles- } \\
\text { terol }\end{array}$ & $161.52 \pm 34.42$ & $156.78 \pm 32.46$ & 0.451 \\
\hline Triglycerides & $145.73 \pm 72.95$ & $143.94 \pm 62.83$ & 0.889 \\
\hline $\begin{array}{l}\text { High-density } \\
\text { lipoprotein }\end{array}$ & $45.17 \pm 10.21$ & $42.84 \pm 10.54$ & 0.233 \\
\hline $\begin{array}{l}\text { Low-density } \\
\text { lipoprotein }\end{array}$ & $88.12 \pm 29.76$ & $76.19 \pm 24.78$ & 0.002 \\
\hline $\begin{array}{l}\text { Very } \\
\text { low-density } \\
\text { protein }\end{array}$ & $25.77 \pm 12.13$ & $26.87 \pm 12.10$ & 0.627 \\
\hline HsCrp & $1.05 \pm 2.46$ & $0.57 \pm 0.43$ & 0.150 \\
\hline
\end{tabular}

Abbreviation: $\mathrm{HsCrp}$, high sensitivity C-reactive protein.

was found statistically significant among cases. HsCRP was also raised among cases compared with controls but was statistically nonsignificant (-Table 3 ). This increase was statistically significant with duration of psoriasis among cases ( - Table 4 ).

On comparison of psoriatic arthritis (Psa; $N=43$ ) and psoriatic (Ps; $N=14$ ) women the following results were found: raised WC (Psa25 (58\%) vs. Ps10 [71\%]), triglycerides (18[42\%] vs. 7[50\%]), blood glucose (12[30\%] vs. $11[78 \%])$, blood pressure (12[28\%] vs. 9[64\%]), HsCRP (14[32\%] vs. 9[64\%]), and CIMT (19[44\%] vs. 6[43\%]).

\section{Discussion}

Our study found majority of the women were Hindus (84\%) and were married (80\%) with literacy status of 56 and $40 \%$ of them belonging to middle class among cases. Among 


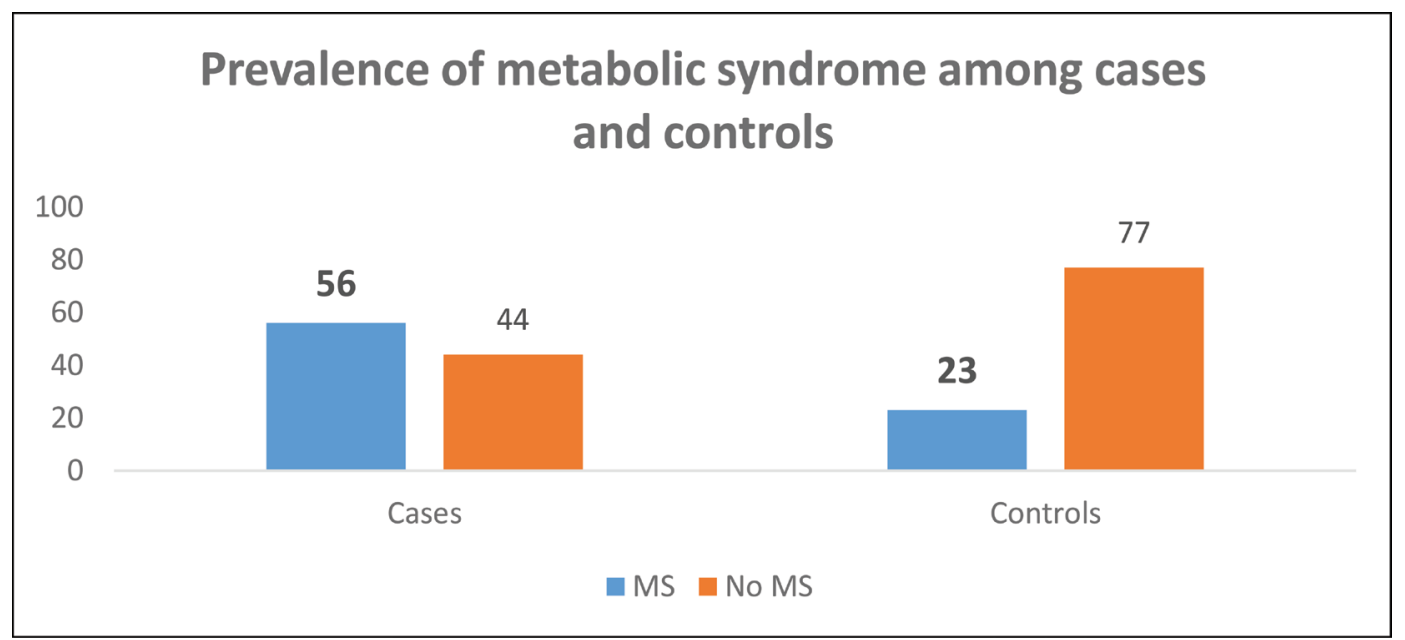

Fig. 2 Prevalence of metabolic syndrome as per updated NCEP ATP III among cases and controls. ATP, adult treatment panel; NCEP, National Cholesterol Education Program.

Table 2 Components of metabolic syndrome among cases and controls

\begin{tabular}{|l|l|l|l|l|}
\hline Component & $\begin{array}{l}\text { Psoriasis cases } \\
N=57\end{array}$ & $\begin{array}{l}\text { Controls } \\
N=57\end{array}$ & Odds ratio ${ }^{\text {a }}(\mathrm{Cl})$ & $p$-Value \\
\hline $\begin{array}{l}\text { Raised waist circumference } \\
(>80 \mathrm{~cm})\end{array}$ & $35(61 \%)$ & $29(50 \%)$ & $0.651(0.309-1.370)$ & 0.347 \\
\hline $\begin{array}{l}\text { Raised triglycerides } \\
(>150 \mathrm{mg} / \mathrm{dL})\end{array}$ & $25(43 \%)$ & $24(42 \%)$ & $0.931(0.443-1.955)$ & 1.000 \\
\hline Low HDL(<50) & $39(68 \%)$ & $44(77 \%)$ & $1.562(0.679-3.595)$ & 0.402 \\
\hline $\begin{array}{l}\text { Fasting blood glucose } \\
(>100 \mathrm{mg} / \mathrm{dL})\end{array}$ & $23(40 \%)$ & $9(16 \%)$ & $0.277(0.114-0.673)$ & 0.004 \\
\hline Raised blood pressure & $21(37 \%)$ & $5(8 \%)$ & $0.165(0.057-0.478)$ & 0.001 \\
\hline
\end{tabular}

Abbreviations: $\mathrm{Cl}$, confidence interval; $\mathrm{HDL}$, high-density lipoprotein.

${ }^{a}$ Odds ratio was calculated using Mantel Haenszel estimate.

Table 3 Elevated biomarker (HsCRP) and carotid intima media thickness among cases and controls

\begin{tabular}{|l|l|l|l|l|}
\hline & Cases & Controls & Odds ratio (Cl) & $p$-Value \\
\hline $\begin{array}{l}\text { Biomarker (Raised HsCrp) } \\
N=42\end{array}$ & $23(55 \%)$ & $19(45 \%)$ & $0.739(0.344-1.586)$ & 0.562 \\
\hline Raised CIMT $(N=26)$ & $25(96 \%)$ & $1(4 \%)$ & $0.023(0.003-0.177)$ & 0.0001 \\
\hline
\end{tabular}

Abbreviations: $\mathrm{Cl}$, confidence interval; $\mathrm{CIMT}$, carotid intima media thickness; $\mathrm{HsCrp}$, high sensitivity C-reactive protein.

controls-Hindus (74\%) and 70\% were married with literacy status of 75 and $49 \%$ of them belonging to upper class.

Psoriasis vulgaris was found among $51 \%$ of the women followed by psoriatic arthritis among $25 \%$. Mean PASI score was $7.14 \pm 3.22$ with $5 \%$ involvement of BSA. Kudligi et al in their study at Hubli also found most common type of psoriasis as psoriasis vulgaris $91 \%$ and mean PASI score as 15.75 which is much higher than our study. Contrast to our study no statistical significance of severity with duration of disease was noted. ${ }^{12}$

Our findings depicted raised mean scores of determinants such as weight, WC, systolic, diastolic blood pressure, total cholesterol, triglycerides, LDL, fasting blood glucose, and HsCRP among cases. Contrast to our study Owczarczyk et al reported triglycerides and systolic blood pressure to be lesser among Polish psoriasis patients. ${ }^{13}$
Table 4 Paired sample t-test between duration and HsCRP

\begin{tabular}{|l|l|l|}
\hline Paired $t$-test & Mean + SD & -Value \\
\hline Duration & $7.75+5.23$ & 0.0001 \\
\cline { 1 - 2 } HsCRP & $1.05+2.46$ & \\
\hline
\end{tabular}

Abbreviation: $\mathrm{HsCrp}$, high sensitivity C-reactive protein; SD, standard deviation.

As per the subcategorization of psoriatic arthritis and psoriasis women we found raised WC, triglycerides, blood glucose, blood pressure, HsCRP, and CIMT in our study. This was similar to Landgren et al in their study among Swedish psoriatic arthritis women where obesity, hypertension, diabetes mellitus, and hyperlipidemia were raised compared with controls. ${ }^{14}$

In our study prevalence of metabolic syndrome among psoriasis patients was 56 and $23 \%$ among controls, respectively as per 
updated ATP III with major components that were statistically significant were raised blood glucose and raised blood pressure. Similar to our study Milčić et al found metabolic syndrome among $50 \%$ of Serbian psoriatic women which is closer to our study. ${ }^{15}$ In Indian set up also Singh et al in their case-control study at Chandigarh found MS among $45.6 \%$ of women psoriatic patients and $15.3 \%$ of women controls with significant components of raised WC, triglycerides, blood glucose, and blood pressure. ${ }^{8}$ These determinants variation can be explained by different ethnicity, different lifestyle, and varying personal habits.

Our study found raised HsCRP among 55\% of the cases and $45 \%$ of controls along with raised CIMT (cases $96 \%$ and controls $4 \%$ ). Similarly Vadakayil et al in their study in south India to determine the role of CRP as a marker of disease severity and cardiovascular risk found CRP to be significantly elevated in psoriatic patients when compared with controls (52 vs. $14 \%$ ). ${ }^{16}$ The level of HsCRP indicates the inflammatory changes occurring at an earlier process of atherosclerosis acting as an added risk factor. Kothiwala in their study also found statistically significant mean scores in both common carotid arteries with cases having scores $0.61 \pm 0.01 \mathrm{~mm}$ and controls $0.37 \pm 0.01 \mathrm{~mm}$, respectively.$^{17}$ This novel finding of increased thickness of CIMT supports the role of inflammatory response as a mechanism that may lead to increased cardiovascular morbidity among psoriatic patients.

\section{Conclusion}

Metabolic syndrome-a major determinant of CVDs was found to have increased trend among psoriasis patients and its components need to be targeted at primary level. Role of HsCRP-the inflammatory biomarker of atherosclerosis and CIMT used as a surrogate marker for measurement of subclinical atherosclerotic changes proved a crucial rise among psoriatic and psoriatic arthritis patients which stresses the benefits of early screening among them as a secondary level of preventive strategy.

This study requires to be followed up as cohorts to strengthen our judgment of causality in near future which could be one of the limitations for the establishment of association.

\section{Audio File}

Audio file for this article is available online at https:// doi.org/10.1055/s-0040-1705661.

\section{Funding}

Prajwalika scholarship stipend, Women in cardiology and related sciences (WINCARS), faculty 2019.

\section{Conflict of Interest}

None.

\section{Acknowledgments}

We extend our thanks to Dr. A. Dhanlakshmi, Department of Biochemistry, ESIC Medical College and Hospital, Dr. Imran Siddiqui, Department of Biochemistry, ESIC Super specialty hospital, Hyderabad for their support, laboratory technician Mr. Venkatesh and all the cases and controls.

\section{References}

1 Farber EM, Nall ML. The natural history of psoriasis in 5,600 patients. Dermatologica 1974;148(1):1-18

2 Naldi L. Risk factors for psoriasis. Curr Dermatol Rep 2013;2: 58-65

3 Global psoriasis atlas-International federation of psoriasis. Available at: http://www.psoriasiscouncil.org. Accessed November 13, 2019global-psoriasis-atlas

4 World Health Organization 2016. Global report on psoriasis. World Health Organization. Available at: https://apps.who.int/ iris/handle/10665/204417

5 Naldi L, Svensson A, Diepgen T, et al; European DermatoEpidemiology Network. Randomized clinical trials for psoriasis 1977-2000: the EDEN survey. J Invest Dermatol 2003; 120(5):738-741

6 Balta I, Balta S, Demirkol S, et al. Aortic arterial stiffness is a moderate predictor of cardiovascular disease in patients with psoriasis vulgaris. Angiology 2014;65(1):74-78

7 Lorenz MW, Markus HS, Bots ML, Rosvall M, Sitzer M. Prediction of clinical cardiovascular events with carotid intima-media thickness: a systematic review and meta-analysis. Circulation 2007;115(4):459-467

8 Singh S, Dogra S, Shafiq N, Bhansali A, Malhotra S. Prevalence of metabolic syndrome in psoriasis and levels of Interleukin-6 and tumor necrosis factor- $\alpha$ in psoriasis patients with metabolic syndrome: Indian Tertiary Care Hospital study. Int J Appl Basic Med Res 2017;7(3):169-175

9 Alberti KG, Zimmet P, Shaw J; IDF Epidemiology Task Force Consensus Group. The metabolic syndrome-a new worldwide definition. Lancet 2005;366(9491):1059-1062

10 WHO Expert Consultation. Appropriate body-mass index for Asian populations and its implications for policy and intervention strategies. Lancet 2004;363(9403):157-163

11 Chobanian AV, Bakris GL, Black HR, et al; National Heart, Lung, and Blood Institute Joint National Committee on Prevention, Detection, Evaluation, and Treatment of High Blood PressureNational High Blood Pressure Education Program Coordinating Committee. The seventh report of the Joint National Committee on Prevention, Detection, Evaluation, and Treatment of High Blood Pressure: the JNC 7 report. JAMA 2003;289(19):2560-2572

12 Kudligi C, Odugouda SG, Kuntoji V. Bhagwat PV, Asati DP, Dhayaneethi E, Kaivalyam. A clinical study of psoriasis and its association with co-morbid conditions. J Pak Assoc Dermatol 2016;26(4):298-305

13 Owczarczyk-Saczonek AB, Nowicki RJ. Prevalence of cardiovascular disease risk factors, and metabolic syndrome and its components in patients with psoriasis aged 30 to 49 years. Postepy Dermatol Alergol 2015;32(4):290-295

14 Landgren AJ, Bilberg A, Eliasson B, et al. Cardiovascular risk factors are highly overrepresented in Swedish patients with psoriatic arthritis compared with the general population. Scand J Rheumatol 2019;49(03):195-199 
Bala et al.

15 Milčić D, Janković S, Vesić S, et al. Prevalence of metabolic syndrome in patients with psoriasis: a hospital-based cross-sectional study. An Bras Dermatol 2017;92(1):46-51

16 Vadakayil AR, Dandekeri S, Kambil SM, Ali NM. Role of C-reactive protein as a marker of disease severity and cardiovascular risk in patients with psoriasis. Indian Dermatol Online J 2015;6(5):322-325
17 Kothiwala SK, Khanna N, Tandon N, et al. Prevalence of metabolic syndrome and cardiovascular changes in patients with chronic plaque psoriasis and their correlation with disease severity: a hospital-based cross-sectional study. Indian J Dermatol Venereol Leprol 2016;82(5):510-518 